\title{
Determinants and Catalysts in Intrafirm Technology Transfer: Learning From Case Studies
}

\author{
Giorgio Petronia', Chiara Verbano², Karen Venturini ${ }^{3}$
}

\begin{abstract}
The sharing of technological knowledge between firms or within the same firm is becoming essential to develop innovations. Although previous studies have investigated the determinants of technology transfer(TT), they have not pointed out the existence of catalysts, i.e. determinants that assume a more crucial role than others in making transfer effective, and which compensate for the weaknesses in other determinants. In this paper, from the analysis of transfer processes within three manufacturing multinationals, three catalysts have emerged: leadership by the top management, anticipated profitability from the adoption of the new technology, and the professionalism of centralized research and development staff.
\end{abstract}

Keywords: intrafirm; technology transfer; determinants; catalysts; multinational companies; case studies

\footnotetext{
1,3 Department of Economics and Technology, University of San Marino, Salita alla Rocca, 44 - 47890 Republic of San Marino. Phone: ' (+378) 0549-888I I I, ${ }^{3}$ (+378) 0549-882500. e-mail: 'petroni@lambrate.inaf.it, ${ }^{3}$ kventurini@unirsm.sm ${ }^{2}$ Department of Management and Engineering, University of Padova, Stradella S. Nicola, 3 - 36 I 00 Vicenza, Italy. Phone: (+39) 0444-9987I I.e-mail: chiara.verbano@unipd.it

ISSN: 07 I8-2724. (http://www.jotmi.org)

Journal of Technology Management \& Innovation (c) Universidad Alberto Hurtado, Facultad de Economía y Negocios.
} 


\section{Introduction}

The rising costs of research and development programs have led 'technology intensive' firms to seek new channels and methods of acquiring and managing the scientific and technological knowledge they wish to incorporate into their products and production processes. In this context, company managements pay special attention to improving methods of transferring technology which is either generated from their own research and development (R\&D), or acquired externally (for example, from suppliers or from companies in other sectors) (Kotabe et al., 2003), and transferred to other divisions within their company. However, the subject of intrafirm technology transfer (i.e. the transfer of technology within the boundaries of a firm, as opposed to interfirm TT, which is transferal between separate organizations) still presents many gray areas and a variety of facets.

Scarce are contributions that highlight the differences between the processes of intrafirm transfer of technologies that have been created and developed within a firm and the processes of internal transfer of externally acquired technologies.

Also worth noting is that internal transfer processes present varying degrees of complexity in relation to the different organizational structures (operational and divisional) that firms have adopted. For example, in order to be effective, practices must take into account not only cultural differences in different countries, but also the distinct requirements of the various lines of products the business units have been constructed to handle. Clearly, this type of transfer structure is similar to that of the interfirm process.

A significant number of contributions to the literature (Malik, 2002; Hansen and Løvås, 2004; Hollenstein and Woerter, 2008; Dinur et al., 2009) deal with factors that determine or positively influence transfer processes (determinants). As detailed below, determinants can be identified, whether they are technical (for example, the level of formalization of a technology), economic (for example, the level of investment needed to carry out effective transfer) or social and organizational (for example, the cultural homogeneity between the transferor and the receiver of the technology). The aim of this paper is to give a contribution to construct a broad framework of the determinants influencing technology transfer that have been identified in the literature, including certain interfirm determinants that could be adapted to the intrafirm setting, and to proceed to qualify them in the context of three multinational firms.

A deeper analysis of the three case studies described in this paper, which looks at the processes of transfer within a large food company, a large chemical company and a machinery manufacturing and engineering company, revealed that among these determinants are a number of essential ones which we call catalysts; i.e., economic and organizational factors that trigger the transfer process. A catalyst is a chemical agent that influences the course of a chemical reaction, reducing the amount of energy required to activate the process and increasing its speed. The term catalyst is also given to activities or events that promote a rapid change within organizations (McAdam, 2000; Skarzauskiene, 2010). We decided to use the term catalyst as a metaphor for certain determinants that are a driving force in activating the process of technological transfer.

This paper has been developed along the following lines: Section 2 provides a synthesis of the literature regarding the determining factors for technology transfer; Section 3 establishes the research objectives and method; Section 4 summarizes the companies examined and the transfer processes they have adopted, and the final Sections 5 and 6 present an analysis of the respective results and conclusions.

\section{Determinants of the transfer process}

The relatively extensive literature has drawn attention to a number of so-called 'determinants' of technology transfer. These consist of technological, organizational and economic factors considered necessary for the successful execution of the process.

The determining factors can be seen as bridges designed to overcome obstacles or resistances that can block transfer (Greiner and Franza, 2003). Using the same metaphor, these bridges may be of greater or lesser length, since the determinants are usually present in varying intensities in the transfer path. For example, the behavior of a technology and its chemical and physical components may be described (formalization) in full or only in terms of some basic aspects. Similarly, the cultural homogeneity between two organizations involved in transfer (transferor and receiver) may concern the company's entire structure or only a specific part of it.

Following the direction taken by Stoneman and MyungJoong (1996) have shown through their empirical analysis the importance of expectations of profitability, such as the productivity of a firm or a product line or the basis for obtaining an important competitive advantage, in motivating company chiefs to accelerate the process of intrafirm transfers. Another economic factor that influences technology transfer decisions is the availability of financial resources. These are essential for coping with the technical and organizational changes that result from adopting new technology. 
The investments required for adapting technology to the needs of individual units are usually fewer in the intrafirm than in the interfirm approach because the internal diffusion of new technology can be executed to the benefit of economies of scale and without radical changes to the process of production and the distribution of products.

Other authors (Antonelli, 1985; Fuentelsaz et al., 2003) have underlined the positive relationship between the efficiency of the internal process of technology transfer and a company's relative smallness in size, although many studies demonstrate the contrary (Urata and Kawai, 2000). Authors such as Fuentelsaz et al. (2003) have studied the structure of the market, revealing that market concentration has a negative effect on the speed of development of the intrafirm transfer process.

A further factor with moderate influence in the intrafirm transfer process is the time lag between the creation of a technology and its reproduction through transfer to subsidiaries (within the firm) or to independent firms (Antonelli, 1985; Amesse and Cohendet, 200I). However, the time lag factor can be included within the technological uncertainty factor, given that the passage of time increases knowledge of the technology, thus reducing uncertainty about it (Fuentelsaz et al., 2003).

Another approach to investigate the technology transfer's mechanisms has focused on the characteristics of the technology being transferred and the organizational structure of the firm designated to receive it. Some authors in particular have highlighted the technical and organizational characteristics of these determinants (Rogers, 2005), while others have stressed the importance of social aspects, such as interaction and communication between partners in the transfer process. Among the technical characteristics, functional homogeneity (which has not yet been studied in the context of intrafirm) is indicated as a factor in promoting technology transfer (Petroni et al., 2010; Venturini et al., 2013). The technology to be transferred can be adopted for conceptually and structurally similar purposes to those realized in the firms and the industrial sector of origin (Amesse et al., 2002). One example of this is the transfer to the medical sector of technology used by astrophysicists for exploring space that share the same purpose of detecting phenomena, which, as in space exploration, are not visible using traditional optical methods.

The level of knowledge of the behavior and performance of the technology being transferred can be classified among the technical determinants (Bach et al., 2002). This knowledge is usually the result of an adequate trial and constitute the know-how that may be owned by the firm's operators or the transferring organization on a personal basis and in a non-written way (tacit knowledge), or it may be formalized (Amesse and Cohendet, 200I). The most favorable level of formalization remains a 'vexed question': formalization represents a very important element in making transfer effective, but at the same time makes it easier to steal. Under certain conditions, the internal transfer process generates a strong stimulus to formalize the technology.

Finally, included among the determining factors should be the level of risk (low, if possible) arising from the use of transferred technology (Greiner and Franza, 2003). This characteristic is directly linked to the degree of testing that has been carried out, and also depends on the potential widespread application that the technology in question offers in conjunction with other emerging technological innovations. This involves an assessment or forecast of its potential period of obsolescence.

Elements of a socio-organizational nature (relating to the organization of both the transferring and adoptive entity) that affect the transfer process can be divided into cultural homogeneity, uniformity of technical language and the effectiveness of the communication and availability of $R \& D$ personnel.A considerable number of studies in the literature (Naranjo -Valencia et al., 20I I; Boh et al., 20I3) have clarified the importance of the value system and the consequent specific behavior (culture) of firms. Culture is evaluated in the context of the transfer in relation to its diversity (distances) between units of a multinational company (for example), this distance influence the effectiveness of coordination mechanisms adopted to transfer knowledge (Ambos and Ambos, 2009).

Finally, homogeneity in technical language and effective communication actually constitutes a component of the corporate culture (Gibson and Smilor, 1991). A certain degree of homogeneity in technical language is a prerequisite for effective communication between entities transferring technology and those receiving it (Sung and Gibson, 2000; Verbano and Venturini, 20I2). As for the presence of an R\&D staff, every transfer project requires the employment of human and financial resources in order to succeed (Bach et al., 2002; Petroni et al., 2010). In particular, the firm or unit adopting the technology requires the support of a technical staff from the transferring unit that is capable of understanding and adapting the technology under adoption. Other authors have focused on organizational variables, underlining, for example, the crucial role of strong leadership in guiding and carrying out the transfer process (Greiner and Franza, 2003; Carmeli et al., 20I I), or the involvement of a centralized management structure (Antonelli, 1985). With specific reference to MNCs, Lee et al. (2010) identify the fundamental role in the transfer process of top management supervision and guidance in integrating the separate business 
units or divisions. Chen et al. (2013) and others (Araújo and Teixeira, 2015), however, have attributed the same dynamic role to the quality of human resources: in other words, to the experiences and tacit knowledge acquired by the technicians and skilled workers of both the transferring and adopting entities involved in the process. Technology transfer is also influenced by the availability of scientists and engineers with appropriate knowledge and inclination (O'Shea et al., 2005). A synthesis of the main determinants reported in literature is presented in Table I.
The effectiveness of the transfer process is clearly affected by the partial or complete presence of the conditions described above and by their intensity. Moreover, a number of these conditions play a crucial role. It is impossible, for example, to carry out the technology transfer process if the financial resources required for technical or organizational investment by the adopting entity are not present, or if the adopting entity has inadequate technical knowledge for using and managing the technology under transfer. The lack of other conditions, such as functional homogeneity or cultural homogeneity, may make the transfer process more difficult. Thus, the relationship established between the various determinants is systemic, since their strong convergence at a high level of intensity is required for every transfer program. In fact, some studies confirm that important effects arise from the interaction between determinants; notably, the effect of each determinant of the technology transfer process depends to a large extent on the state of each of the other determinants (Hansen and Løvås, 2004; Dana, 2007).

\begin{tabular}{|l|l|}
\hline $\begin{array}{l}\text { Structural } \\
\text { Determinants }\end{array}$ & $\begin{array}{l}\text { Company size (Fuentelsaz et al., 2003) } \\
\text { Market structure (Fuentelsaz et al., 2003) }\end{array}$ \\
\hline Technical \\
Determinants & $\begin{array}{l}\text { Level of complexity of the technology (Urata and Kawai, 2000) } \\
\text { Functional homogeneity (Petroni et al., 20I0;Verbano and Venturini, 20I2) } \\
\text { Level of empirical knowledge of the technology (by the transferor) (Malik, 2002) } \\
\text { Level of formalization (by the transferor) (Urata and Kawai, 2000) } \\
\text { Level of technical risk (Fuentelsaz et al., 2003) }\end{array}$ \\
\hline $\begin{array}{l}\text { Socio- } \\
\text { organizational } \\
\text { Determinants }\end{array}$ & $\begin{array}{l}\text { Cultural homogeneity (between the transferring and adopting entities). } \\
\text { Efficiency of communication (Malik, 2002) } \\
\text { Availability of a R\&D staff (by the adopting entities) (Cummings and Teng, 2003) } \\
\text { Professionalism of the transferring company's technical staff (Bach et al. 2002; Petroni et al., 20I0) } \\
\text { Strong leadership by top management (Carmeli et al., 20II) }\end{array}$ \\
\hline $\begin{array}{l}\text { Economic } \\
\text { Determinants }\end{array}$ & $\begin{array}{l}\text { Anticipated profitability (Stoneman and Myung Joong, I996) } \\
\text { Availability of financial resources to address technical and organizational changes required by the } \\
\text { adoption of new technology (Malik, 2002) }\end{array}$ \\
\hline
\end{tabular}

Table I. Summary of the main determinants of intrafirm technology transfer (he two determinants labeled "interfirm" have not yet been validated in the intrafirm TT domain). 


\section{Research objectives and methodology}

Through an analysis of the case studies of three specifically European firms, the results of which are reported below, this study attempts to explore the conditions and mechanisms that make intrafirm technology transfer possible. The firms examined (the following section provides a brief profile of each) are widely present in international markets, also in the form of production units.

The large multinational companies selected for the study were not chosen as the most representative within their sector, but for their ability to illuminate the research questions proposed (Eisenhardt, 1989).
The criteria for selecting these companies were as follows:

I. All MNCs operate in a different manufacturing sector, conduct TT between units operating in different countries and develop a variety of product lines;

2. They effectuate TT at different levels of the organizational structure: between production units (Case B), between business units (Case $A$ ) and between divisions that each include various business units (Case $\mathrm{C}$ );

3. They possess one or more R\&D units and have staff that can handle technology transfer.

Once the MNCs had been selected, the process of data collection took place as shown in Figure I.

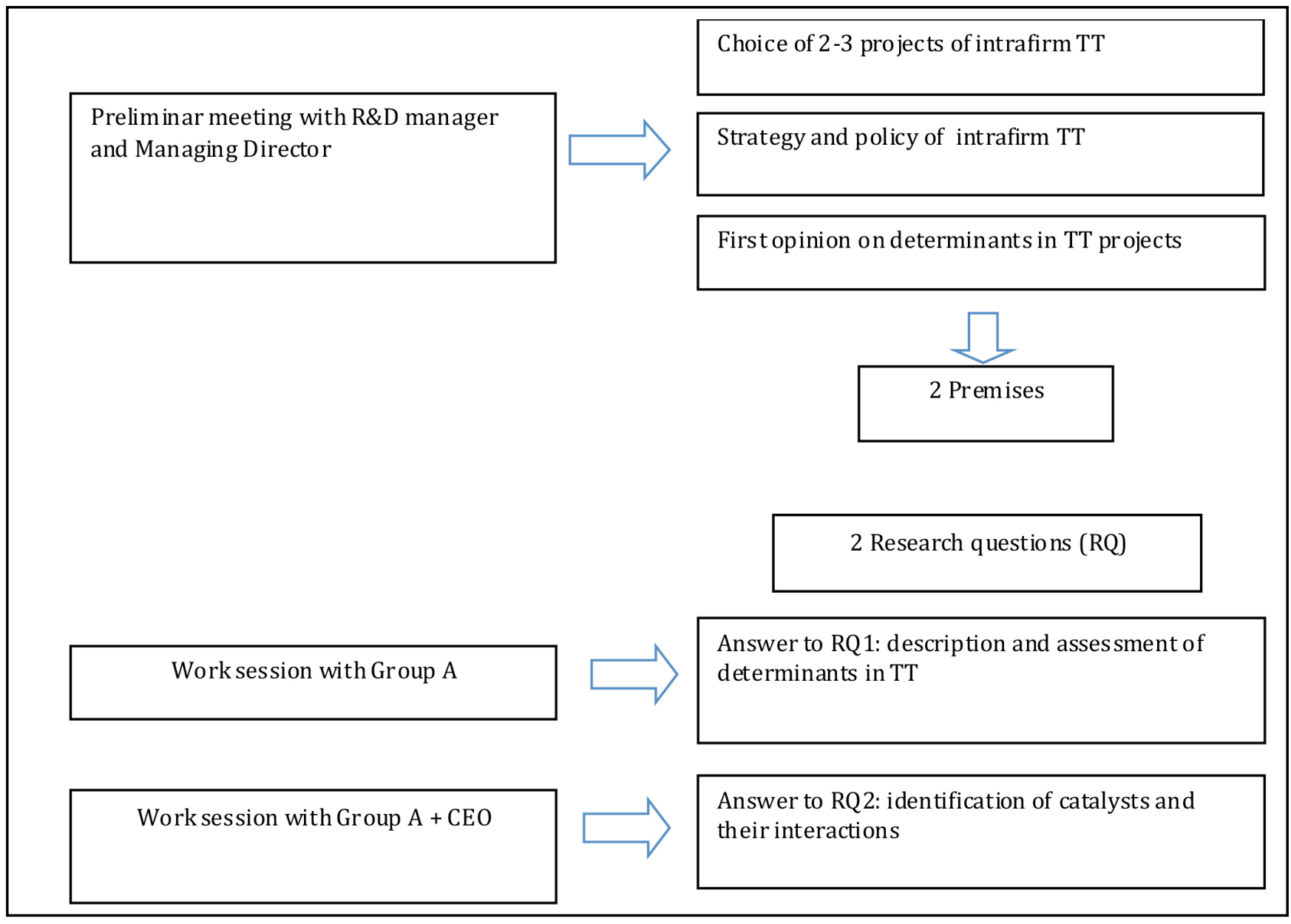

Figure I.The process of data collection 
Since the objective of this study was to identify the intensity of the determinants within the transfer process, the unit of observation used was the individual transfer project. In a preliminary meeting with the R\&D Manager and the Managing Director of the companies, 2-3 transfer projects were selected. The shared characteristics of these projects are that they took place within the company, they involved the transfer of internally generated technology (B and $C$ ), and externally acquired technology (A), and the transfer was successful (i.e. the technology or technique was adopted within a short period of time). The meeting was also motivated by the need to gain a broad understanding of the strategies and processes of internal transfer adopted by the companies involved, and to test the determinants. Moreover, the respondents were asked to express their opinions, in the base of their experience, about the variables differentiating the determinants in intrafirm TT projects and the existence of different level of intensity in the determinants. The report of the meeting, which was taped and then transcribed, in addition to a prior study of intrafirm TT in MNCs, formed the background to formulating two premises. These premises, verified through the following analysis, can be formulated as follows: I. the intrafirm approach can be classified according to whether the technology was created within the multinational's R\&D laboratories or acquired from an external supplier. The intrafirm process can be further categorized (models) according to the hierarchical level of the units involved in the transfer. 2.Among the determinants examined in the literature (Table I), particular determinants (which we called catalysts) may emerge, whose function is to stimulate and prioritize the transfer process, compensating for any lack of intensity in the other determinants.

The research questions, formulated on the basis of these premises, were as follows:

I. What are the determining factors in the transfer process in each of the three cases examined, and what are their levels of intensity? Are there differences in the determinants in the case of different models of intrafirm TT? Are there differences between the determinants in cases where the technology was generated internally and where it was acquired externally by the MNCs?

2. Do catalysts exist, and if so, which were they in the process of technology transfer in each of the firms studied? If they are present, how do they affect the process of technology transfer?
Characterization of the sample was made following a preliminary study of some documents such as productmarket reports, annual reports, organizational structure, and other information available on the web pages of the MNCs. We prepared two different questionnaires, each aimed to answer one of the two research questions. We developed pilot designs of the two questionnaires and pre-tested them in a face-to-face interview with the managing director of each firm. In a first work session a group of 3 members of the senior management (Group A: Managing Director, Vice President of Research and Development and Vice President in charge of Organization and Human Resources) were invited for each project to give a qualitative answer to the questions reported in Table 2, investigating the influence of the determinants emerged from literature review. 


\begin{tabular}{|c|c|}
\hline $\begin{array}{l}\text { Technical } \\
\text { determinants }\end{array}$ & $\begin{array}{l}\text { Functional homogeneity: did the transferred technology have a field of application with similar func- } \\
\text { tionality features to the original ones? } \\
\text { Level of the transferor's empirical knowledge of the technology:Was the technology new for your } \\
\text { firm? How long have you been using it and how have you consolidated your knowledge of it (train- } \\
\text { ing courses, testing, etc.)? } \\
\text { Level of formalization by the transferor: Is there a clear, formal documentation on how the technol- } \\
\text { ogy functions? If not, why not? } \\
\text { Technical risk: Did the technology function in a clear, comprehensible and demonstrable way? Once } \\
\text { the transfer was completed, did the technology work well in its new operating environment? }\end{array}$ \\
\hline $\begin{array}{l}\text { Socio- } \\
\text { organizational } \\
\text { determinants }\end{array}$ & $\begin{array}{l}\text { Cultural homogeneity: Is there a system of shared cultural values between the transferring and } \\
\text { adoptive entities? Is the technical language similar? } \\
\text { Effectiveness of communication: Have formal systems of information and communication been } \\
\text { adopted even between geographically distant and culturally different units? Do informal systems of } \\
\text { communication also exist between the entities involved? } \\
\text { Availability of R\&D staff: Does the receiving entity have a Research and Development laboratory? If } \\
\text { not, does it have technicians and scientists involved in research? } \\
\text { Professional level of technical staff:What was the training of the technical staff involved in the } \\
\text { transfer? Were they chosen on the basis of academic experience (PhD, Masters or other university } \\
\text { degrees) and scientific experience (participation in European and/or international projects)? } \\
\text { Leadership:Was there strong involvement by top management in the transfer? Did the latter guide } \\
\text { the entire process with determination? }\end{array}$ \\
\hline $\begin{array}{l}\text { Economic } \\
\text { determinants }\end{array}$ & $\begin{array}{l}\text { Anticipated profitability: What benefit-cost relationship is expected as a result of the technology } \\
\text { transfer? } \\
\text { Availability of financial resources: Which financial resources? Were external contributions obtained } \\
\text { (European or regional funding for projects etc.) with regard to the transfer? }\end{array}$ \\
\hline
\end{tabular}

Table 2. List of questions formulated to explain the determinants 
Further, in the same work section, we asked respondents to translate the qualitative evaluation in a scoring scale from I (low intensity positively influencing the TT project) to 3 (high intensity).

In order to answer the first research question regarding the differences in the determinants, in the case of different models and sourced of the technology, the answers obtained were aggregated at company level, considering both the average value of the scoring and the qualitative evaluation of each respondent for each project, and verifying the final assessment with the interviewed.This step was facilitated by a good level of homogeneity among answers obtained for projects developed within the same company.

A second special work session was organized in which the top three executives mentioned above were joined by the Chief Executive Officer (CEO) (Group AI) to answer to the second research question. The motivation for involving the CEO was to confirm the findings from the meeting with the first group (A) and because, as the most authoritative figure in the firm (and one who holds a crucial role in the transfer process), his presence was essential in identifying the catalysts (Hedlund, 1994). The meeting entailed the identification of the catalysts and the impetus they produce in achieving the transfer process. The working group identified the catalysts both in terms of their clearly superior value compared to other determinants-and hence their greater influence on the transfer process-and because they responded to the questions: "Why was the transfer process successful despite the low value of some determinants? Do determinants exist that can facilitate and propel the transfer process, thus compensating for the low intensity of other determinants?" Also in this case the analysis was conducted focusing on each TT project, and then aggregating the results at company level, in that the projects of the same company, for their characteristics, belong to the same model of TT. The researchers then produced an initial summary, which they discussed and verified together.To maintain consistency, one researcher processed all the data. During the period of data collection a continuous iterative process took place based on the analysis of interview notes and documentary information. Final summaries and interpretations were discussed jointly to validate the findings.

\section{Companies profile}

Listed below are the profiles of the three firms whose intrafirm technology transfer processes have been the subject of this study. The profiles are deemed essential because each contains the necessary information for describing the transfer process and the company context in which it took place.

\section{Company A}

a) Products and Markets. This is a major food company that has its headquarters in Europe and operating units both in major European countries (Italy, France and Germany) and in Japan and the United State, where it is the leader in pasta production. In 2010 its turnover was 4.029 million Euros, with a profit of 27 million Euros. The company has 14,000 employees and its main competitors are big food companies such as Kellogg's, Kraft, Nestlè and Danone.

b) Technological structure of the company. The technological structure is highly centralized in that it is under the direct management of the CEO. The sections "Research and Technology", "Product Development", "Engineering and Processes and Quality Assurance" count a total of 310 people divided among a wide range of laboratories: chemistry, physics, nutrition, sensory analysis and pilot systems biology. Such an area of expertise is justified by the typical needs of food companies, whose wide range of problems span many scientific disciplines.

c) Sources of innovation and technology transfer. Technological innovations arise from internal research and development facilities and often from providers, and are closely linked to the creation and development of new products. Frequently, suppliers' suggestions for new product ideas and the technologies related to these are subjected to analysis and tests performed by the Technological Research and Development staff, who first modify and formalize them before proposing them to the CEO for industrial launch. In the overall evaluation of the proposals, the CEO also collaborates with marketing experts working within the business units. The transfer process within the company is therefore strongly top-down.

The process studied in the course of this research was the transfer of the following technologies between business units: rapid labeling methods and stabilization techniques (related to the conservation of foods), such as acidification (lowering the $\mathrm{pH}$ of the food below the tolerated value for microorganisms), oxygen control, electromagnetic radiation such as X-rays, gamma and ultraviolet rays, and High Hydrostatic Pressure. These technologies were introduced into the company through collaboration with universities, suppliers and the company's own R\&D laboratory. 


\section{Company B}

a) Products and markets. The second company (with 50 production units outside Italy) operates in the chemistry and building materials sector, producing and marketing its products in 54 countries. The 2010 financial report showed a turnover of 1.6 billion Euros and a net profit after tax of 27.4 million Euros.

The 2010 turnover was derived as follows: one-third in Italy, one-third in other European countries, one-third in the U.S. and the rest in the Far East. Currently, the company has no global competitor, but certain product lines compete with those of BASF, Saint Gobain and the Swiss company Weber Bruin.

b) Technological structure. Out of a total of 8,000 employees, 690 are researchers and technologists. The company in question spends about $6 \%$ of its turnover on research and development. The Central R\&D Laboratory (whose head is the CEO) absorbs about $50 \%$ of the total research budget and exercises a strong leadership over the other international laboratories. The entire staff of researchers and technologists is mainly engaged in applied research (typically new products) and the development of new applications, whereas basic research is assigned to university centers. The recruitment of researchers and technologists occurs primarily through an extensive network of contacts that the company has established with a number of European universities.

c) The process of technology transfer. New products, or improvements to existing products, are generated primarily in the firm's Central R\&D Lab, where they are also tested. The transfer of knowledge to the various units usually happens though temporary transfer of researchers and technologists from the Central R\&D to units operating in different countries and the training of local researchers and technicians, which takes place annually at the Central R\&D Lab.

For reasons of confidentiality, little emphasis is given to the formalization and related dissemination of technical procedures.

The specific transfer processes studied in this research were as follows:

The technique for detecting the chemical and physical characteristics of the substrate of external building surfaces before applying protective coatings;

Techniques for making and applying composite adhesives (with the inclusion of nanopolymers) for artistic and cultural works.

\section{Company C}

a) Products and markets. This firm is a subsidiary of a multinational engineering company and operates in the field of machinery manufacturing and fabricated metal product manufacture, mainly for the chemical industry. Its headquarters are in Europe, and it has 500 employees. In 2010, its turnover was 2.6 billion Euros and its net profit after tax was 65 million Euros. Twenty-five percent of the turnover was obtained in Europe, $25 \%$ in China and the Far East, and $50 \%$ in Arab countries in the Middle East.

b) Technological structure. The firm has a team of researchers and technologists with notable expertise in designing machines and plants that operate at high pressure and high temperatures. The group is also very active in the field of applied research into the use of materials (steel, titanium, molybdenum, morel etc.), with particular proficiency in chemistry and physics (considerable competency has been developed in the field of welding). The team of researchers and technologists are managed directly by the CEO.

c) Sources of innovation and technology transfer. This multinational company bought the company that owns the technology in order to construct its own heat exchangers, which demonstrate a substantial improvement over the performance of traditional engineering solutions by obtaining a much greater heat exchange surface from the same dimensions, while significantly reducing the frequency of the need for internal cleaning of the heat exchangers, thus achieving a considerable reduction in maintenance costs and equipment.

This new technology was transferred from one division to another (located in a different country), mainly through the direct support of technical experts.

The following technologies were studied as the subject of internal transfer:

- Manufacturing technology for non-linear heat exchangers used to convey fluids at particularly high pressures and temperatures,

- $\quad$ Adoption of new welding systems for advanced materials,

- $\quad$ Adoption of new systems for anchoring heat exchangers to ensure the functional reliability and stability of the tubular parts.

A summary of the salient features of the cases examined is presented in Table 3. 


\begin{tabular}{|c|c|c|c|}
\hline & Firm A & Firm B & Firm C \\
\hline Sector & Food & $\begin{array}{l}\text { Chemicals for the building } \\
\text { sector }\end{array}$ & machinery manufacturing and engineering \\
\hline Main products & $\begin{array}{l}\text { Pasta, bakery goods, } \\
\text { sauces }\end{array}$ & Resins, adhesives, mortars, paints & reactors and heat exchangers \\
\hline Operating units & $\begin{array}{l}40 \text { in Europe and } \\
\text { USA }\end{array}$ & 50 production units & In Europe, Asia and Middle East \\
\hline Size & $\begin{array}{l}\text { Large multinational: } \\
\text { Around } 15,000 \\
\text { employees }\end{array}$ & $\begin{array}{l}\text { Large multinational: } \\
\text { Around } 10,000 \text { employees }\end{array}$ & $\begin{array}{l}\text { Large multinational: } \\
500 \text { employees }\end{array}$ \\
\hline $\begin{array}{l}\text { Organizational } \\
\text { structure }\end{array}$ & Per business unit & Functional & Divisional \\
\hline $\begin{array}{l}\text { Technological } \\
\text { structure }\end{array}$ & $\begin{array}{l}\text { Various units, all } \\
\text { dependent on one } \\
\text { centralized unit }\end{array}$ & $\begin{array}{l}\text { Central laboratory and } \\
\text { Decentralized research centers }\end{array}$ & Centralized unit \\
\hline $\begin{array}{l}\text { Sources of inno- } \\
\text { vation }\end{array}$ & R\&D and suppliers & R\&D & $\begin{array}{l}\text { R\&D and technology } \\
\text { acquisitions }\end{array}$ \\
\hline TT model & $\begin{array}{l}\text { Between various } \\
\text { business units } \\
\text { (inter-BU) }\end{array}$ & $\begin{array}{l}\text { From the main production unit } \\
\text { of the headquarters to the pro- } \\
\text { duction units in other Countries } \\
\text { (inter-production units) }\end{array}$ & $\begin{array}{l}\text { From one division to another (inter-divisional) } \\
\text { in a different Country }\end{array}$ \\
\hline $\begin{array}{l}\text { TT projects } \\
\text { analyzed }\end{array}$ & $\begin{array}{l}\text { food stabilization } \\
\text { and rapid labeling } \\
\text { methods }\end{array}$ & $\begin{array}{l}\text { Detection techniques for } \\
\text { building surfaces; techniques for } \\
\text { composite adhesives application }\end{array}$ & $\begin{array}{l}\text { Heat exchangers manufacturing technology; } \\
\text { new welding system; anchoring heat exchang- } \\
\text { ers systems }\end{array}$ \\
\hline $\begin{array}{l}\text { Origin of trans- } \\
\text { ferred } \\
\text { technology }\end{array}$ & External & Internal & Internal \\
\hline
\end{tabular}

Table 3. Characteristics of the cases examined 


\section{Discussion and implications}

\section{Determinants and their level of intensity}

Table 4 displays the results of the evaluations made by the group of senior managers from each of the three firms (Group A) regarding the determinants involved in the transfer process and their particular intensity. the need to formalize the technology under transfer, the effectiveness of communication between the entity transferring and the entity adopting the technology, and the presence of a staff of researchers and technologists in the adopting firms. In addition, a low value was assigned to the determinants 'technical risk' and 'availability of resources'. The low level of formalization of the technology being transferred is essentially due to fear of its theft by engineering

\begin{tabular}{|c|c|c|c|c|}
\hline & Determinants & Firm A & Firm B & Firm C \\
\hline \multirow{4}{*}{ 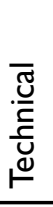 } & I. Functional homogeneity & $\mathrm{XX}$ & $\mathrm{XX}$ & $\mathrm{XX}$ \\
\hline & 2. Empirical knowledge of the technology under transfer & $\mathrm{XXX}$ & $\mathrm{XX}$ & $\mathrm{XX}$ \\
\hline & 3. Level of formalization & $\mathrm{X}$ & $x$ & $\mathrm{X}$ \\
\hline & 4. Level of technical risk & $\mathrm{XXX}$ & $\mathrm{XX}$ & $\mathrm{XX}$ \\
\hline \multirow{5}{*}{ 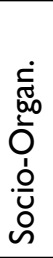 } & 5. Cultural Homogeneity & $\mathrm{XX}$ & $\mathrm{XX}$ & $\mathrm{XX}$ \\
\hline & 6. Effectiveness of communication & $\mathrm{X}$ & $\mathrm{XX}$ & $\mathrm{X}$ \\
\hline & 7. R\&D availability in the receiving unit & $\mathrm{x}$ & $\mathrm{XX}$ & $\mathrm{x}$ \\
\hline & 8. Professionalism of staff at the central R\&D unit & $\mathrm{XXX}$ & $X X X$ & $\mathrm{XXX}$ \\
\hline & 9. Top management leadership & $\mathrm{XXX}$ & $X X X$ & $\mathrm{XXX}$ \\
\hline \multirow{2}{*}{ 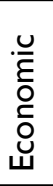 } & $\begin{array}{l}\text { 10. Availability of resources to provide new investments for addressing changes } \\
\text { caused by new technology }\end{array}$ & $x X$ & $\mathrm{X}$ & $X X$ \\
\hline & II. Positive evaluation of the benefits/costs relationship & $\mathrm{XXX}$ & $X X X$ & $\mathrm{XXX}$ \\
\hline
\end{tabular}

Table 4. Determinants involved in the transfer processes and their intensity (the scale used for the evaluation ranges from I (low intensity positively influencing the TT process) to 3 (high).

In answer to Question I, the data reveals three determinants were present at a high degree of intensity in the transfer processes examined: the professionalism of the technical staff, the leadership of top management and the profitability of the investment in technology. These were followed three further determinants: a good empirical knowledge of technology transfer, functional homogeneity (i.e. the use of similar technology in different product lines) and strong cultural homogeneity. This last factor emerges in all three case studies. With regard to the food company, it appears to be important that the various technologies transferred to its internal organizational units were originally acquired from suppliers, who can certainly be considered culturally homogeneous, even by the internal adopting units.

By contrast, other determinants present in the transfer processes undertaken by the three corporations emerge as having been rather weak in intensity. The following determinants demonstrated a particularly slight influence: firms or business competitors, thus a need for secrecy is perceived. Obviously, the lack of a written description of the behavior of the technology and the elements that compose it creates a rather difficult communication process between the units transferring and the units adopting the technology. Moreover, for those involved in the process, it leads to uncertainty about the technical outcome of the transfer. Nonetheless, this does not contradict the high level of knowledge of the technology held by a few people (the classic practitioners), whose involvement in the course of the research has been shown to be essential to the successful outcome of the transfer process.

Lastly, in the cases examined, it was found that communication between the transferring and adopting organizations was not as important a determinant as had been expected in the technology transfer process, perhaps due to the strong leadership that guided the process. A constant effort is therefore required in order to improve 
the communication process between the actors involved in the transfer by providing continuous training, and developing awareness of the technical and functional characteristics of the technologies to be transferred. The presence of R\&D structures within the adopting organizations was not found to be crucial in the process of TT due to the top-down involvement of staff from the centralized R\&D unit which, due to the professionalism of its personnel, supervised swift and effective testing of the new technology. Finally, even technical risk appears to be less influential in intrafirm processes, since the technology has already been tested and entrusted to the ability and skills of the internal technologists.

An analysis of the results does not indicate substantial differences in the level of intensity of the determinants for different types of transfer. Indeed, a certain general consistency emerges in the order of priority of the intrafirm determinants. Even the diversity of the technology (whether originated internally or acquired externally by the company) does not seem to be a condition for significant differentiation of the factors influencing the transfer. Exceptions are the empirical knowledge of the technology and the level of technical risk. Company A, which acquires technology externally, gives the determinant 'empirical knowledge of the technology' more weight, because it knows less about the technology than do Companies $B$ and $C$, which have developed their technology internally. The level of technical risk in the case of Company $\mathrm{A}$ also has a higher score because the testing phase is brief, limited and must be repeated internally.

\section{Catalysts and their systemic action}

Table 5 shows the results of the evaluations carried out by groups of experts that included the CEO for each firm (Group $\mathrm{Al}$ ). By establishing the degree of intensity of the determinants listed above, these groups were asked to identify and classify, in order of importance, the catalysts that had successfully triggered the process of intrafirm transfer (answer to the second research question).

From the evaluation, three unequivocal catalysts emerge, namely:

- $\quad$ Strong leadership by top management and/or the central R\&D unit, which answers directly to the CEO, who oversees technology strategy,

- $\quad$ The prospect of obtaining a significant competitive advantage from new technology,

- The particular expertise of a number of technologists who significantly improve the performance of the technology transferred.

\begin{tabular}{|l|l|l|}
\hline Firm A & Firm B & Firm C \\
\hline $\begin{array}{l}\text { I. Direct involvement of top } \\
\text { management }\end{array}$ & $\begin{array}{l}\text { I.Professionalism of the technicians } \\
\text { at the centralized R\&D unit and } \\
\text { training courses for the adopting unit }\end{array}$ & $\begin{array}{l}\text { I.Professionalism of technicians at } \\
\text { the central R\&D unit }\end{array}$ \\
\hline $\begin{array}{l}\text { 2. Considerable competitive advantage } \\
\text { anticipated }\end{array}$ & $\begin{array}{l}\text { 2. Direct involvement of top } \\
\text { management }\end{array}$ & $\begin{array}{l}\text { 2. Considerable competitive } \\
\text { advantage anticipated }\end{array}$ \\
\hline $\begin{array}{l}\text { 3. Professionalism of the technicians at } \\
\text { the centralized R\&D unit, and training } \\
\text { courses for the adopting unit }\end{array}$ & $\begin{array}{l}\text { 3. Considerable competitive advan- } \\
\text { tage anticipated }\end{array}$ & $\begin{array}{l}\text { 3. Strong leadership of the } \\
\text { central R\&D staff }\end{array}$ \\
\hline
\end{tabular}

Table 5. Catalysts identified by Group AI 
These catalysts are listed for each of the individual transfer processes according to a scale of priorities, and their role exhibits varying gradations. For example, in the case of Company $\mathrm{A}$, the direct involvement of top management in the process was positively assessed, whereas in the case of Companies B and C, the evaluators emphasized the importance of the professionalism of the main staff in the $R \& D$ unit, who offer training courses for the adopting entities (courses and special seminars on the characteristics and use of the technology under adoption). Ranked next for both Company $A$ and Company $C$ was the importance of costeffectiveness in technological investment, whereas Company $B$ cited the involvement of top management in guiding the transfer. The final catalyst emphasized by Company $A$ was the professionalism of the technical staff of the centralized R\&D unit; for Company B, it was economic considerations and for Company $\mathrm{C}$, the leadership of the staff in charge of $R \& D$, who were assigned by the top management to follow the transfer. Even in this case, substantial differences do not emerge between the types of intrafirm transfer.

These catalysts develop a systemic action, directing behavior toward the common goal and assisting in overcoming any obstacles that hamper the success of the process, such as uncertainties in the decision-making process, technical uncertainties, the level of risk, shortcomings in professional culture and so forth.
Therefore, what was the synergic dynamic activated by the catalysts? Clearly, they assisted in overcoming the lack of intensity of certain other determinants (Figure 2). In particular, the expectation of important economic benefits arising from the transfer project prompted the top management team in each company to decide in favor of carrying out the projects, thus prevailing over the uncertainties of technical risks feared by the managements of the adopting units, the ineffectiveness of communication and the limited availability of financial resources. This strong decision-making attitude by top management even overcame the resistance that the adopting unit heads showed towards the investments that had to be made to modify certain operating methods (changes in machinery, raw materials, maintenance procedures etc.) in order to accommodate the newly transferred technologies. The top management's decisions were also supported by the highly centralized research and technology departments, which in all three companies are under the direct control of top management.

Finally, uncertainties arising from both the lack of formalization of the transferred technologies and the limited availability of technical staff in the adopting organization were overcome by the direct involvement in the transfer process of a team of staff from the main research and technology department, who had acquired good knowledge and empirical expertise in dealing with the technology under transfer.They were also responsible for the intensive training programs organized for the technicians in the adopting units.

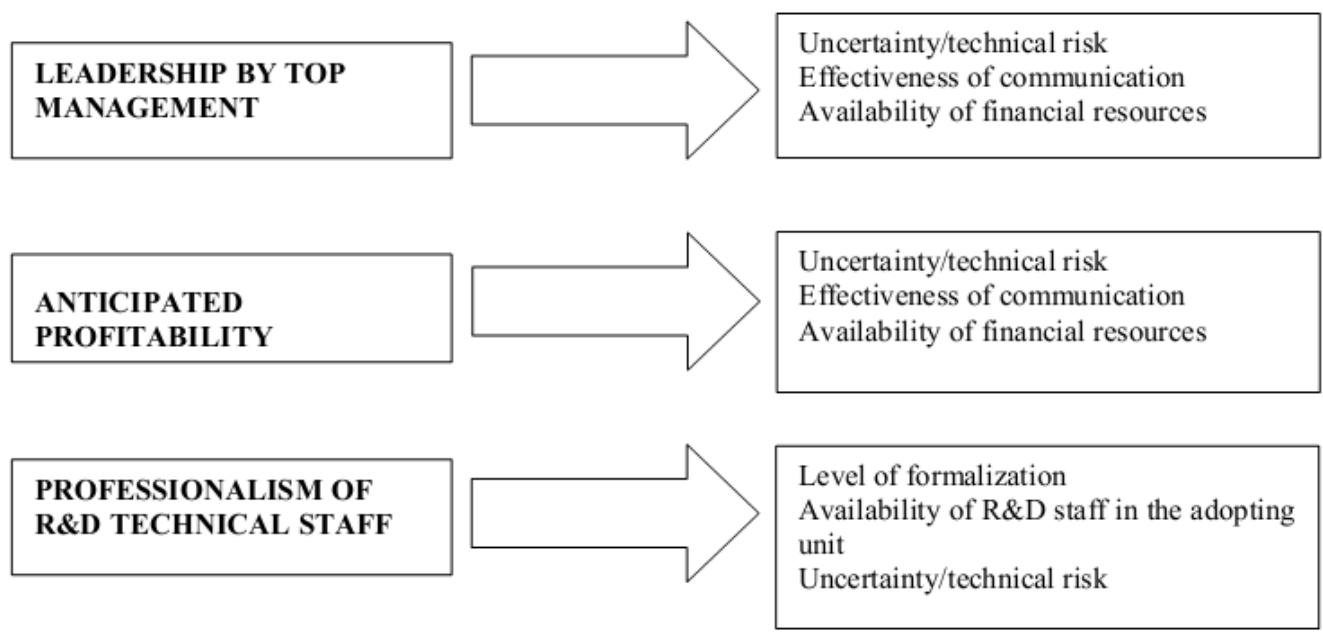

Figure 2. Systemic action of catalysts

ISSN: 07I 8-2724. (http://www.jotmi.org) 


\section{Theoretical implications}

The findings from this study add a contribution, with academic and managerial implications, to the historic debate over centralized or decentralized R\&D, providing further confirmation of the importance of developing a centralized R\&D staff (to which technicians from the business units in multi-divisional companies may be added). In other words, the central R\&D unit plays a fundamental role as a pool of knowledge and skills that can answer the needs of the business units by providing a wide range of support activities, specifically designed projects, training, and the transference of tacit knowledge - at times deliberately non-formalized.

Secondly, this study presents a broad synthesis and further evaluation of the intrafirm determinants studied in the literature. An original finding of the study is the addition of two new determinants not previously evaluated in the process of intrafirm technology transfer; in particular, the determinant "functional homogeneity", formerly only evaluated with regard to the transfer of space technologies to small and medium-sized firms (Verbano and Venturini, 2012). Thus it appears that when the functionality of the new technology is similar to one that preceded it, the transfer is easier.

The second new determinant is the "professionalism of the transferor's technical staff", measured in terms of their technical and scientific training. This determinant is extremely important for making transfer processes effective within a multinational firm, and is therefore described as a catalyst. Furthermore, it is clear that the forces driving TT are more economic and socio-organizational than technical in nature.

A further new finding of the present study, compared to previous literature on the subject, is that intrafirm TT processes are modeled according to the hierarchical level of the TT (inter-divisions, inter-business units and interfunctions), and according to whether the technology originates from within the multinational (in its own R\&D laboratories) or is acquired from an external supplier.

This research is limited by the fact that only three case studies have been considered. Although this number can provide initial indications, it is not sufficient to advance a generalization of the results. The determinants at work in the different types of intrafirm TT require further analysis and confirmation through additional case studies, including ones in other industrial sectors, notably high-tech companies and service industries, in order to provide a comprehensive understanding of the phenomenon.

\section{Managerial implications}

This study informs managers that determinants can have a different weight in influencing technology transfer processes, and that some factors more than others contribute to activating and accelerating internal technology transfer. Catalysts enable a transfer to take less time, even when the multinational in question includes weak determinants that are deemed necessary. The identification of catalysts in the TT process bears considerable managerial and organizational implications for the successful planning and implementation of intrafirm TT projects.

\section{Conclusions}

After a thorough review of the literature, this paper intends to verify the determinants identified in the context of intrafirm and interfirm technology transfer in relation to three cases of intrafirm MNCs. In detail, an analysis of the internal transfer projects of the three multinationals studied has led to the following considerations.

Despite the fact that one would tend to expect fewer critical cultural determinants in the intrafirm as opposed to the interfirm context, the analysis conducted reveals that certain determinants remain significant (even though less influential than the first three determinants in Table 5). These are the availability of financial resources and the level of technical risk. On the other hand, the level of formalization of the technology, the effectiveness of communication and the availability of R\&D staff in the adopting unit seem to have little influence.

The technical determinants that facilitate transfer are primarily related to a high level of empirical knowledge of the technology under transfer and good functional homogeneity (i.e. the use of the technology in applications with similar functionality in different product lines). Equally important is the presence of a high degree of cultural homogeneity between the transferor and the receiving unit.

An analysis of the cases studied allows a further differentiation within the intrafirm transfer context, based on the hierarchical level of the units involved (inter-divisional, interbusiness units, inter-functional) and the internal or external origin of the technology transferred (Table 6). 


\begin{tabular}{|l|l|l|l|}
\hline Intrafirm TT models & Determinants & Catalysts & \\
\hline $\begin{array}{l}\text { Origin of the } \\
\text { technology transferred }\end{array}$ & Internal & $\begin{array}{l}\text { More empirical knowledge of the } \\
\text { technology and lower risk }\end{array}$ & $\begin{array}{l}\text { Top management involvement } \\
\text { Considerable competitive advantage } \\
\text { anticipated } \\
\text { Professionalism of R\&D central staff }\end{array}$ \\
\hline $\begin{array}{l}\text { Hierarchical level of } \\
\text { the TT }\end{array}$ & External & $\begin{array}{l}\text { Less empirical knowledge of the } \\
\text { technology and higher risk }\end{array}$ & \\
\hline & $\begin{array}{l}\text { Inter-divisions } \\
\text { units }\end{array}$ & $\begin{array}{l}\text { Low differences in general (inter- } \\
\text { more similar) }\end{array}$ & \\
\hline & Inter-functions & & \\
\hline
\end{tabular}

Table 6 Intrafirm technology transfer models 
In the first case (differences between hierarchical level of intrafirm TT), the analysis has not identified any substantial difference between the determinants, even if Cases $A$ and $C$ are more similar because TT is at a higher hierarchical level within these MNCs. In the second case, (the internal or external origin of the technology transferred) a difference, albeit slight, has been revealed in relation to two determinants. Company B, which acquires technology externally, gives greater weight to knowledge of the technology and the level of technical risk, in view of its limited knowledge of the technology's behavior.

However, three highly influential factors (called catalysts) have emerged which are able to activate a systemic impetus on the transfer and positively affect the success of the process.

\section{References}

AMBOS, C., Ambos, B. (2009). The impact of distance on knowledge transfer effectiveness in multinational corporations. Journal of International Management, 15(I), I-I4. doi:http://dx.doi.org//0.1016/j.intman.2008.02.002

AMESSE, F. Cohendet, P. (200I). Technology transfer revisited from the knowledge-based economy. Research Policy, 30, 1459-1478. doi: http://dx.doi.org//0.1016/s00487333(01)00162-7.

AMESSE, F., Cohendet, P., Poirier, A., Chouinard, J. (2002). Economic effects and spin-offs in a small space economy: the case of Canada, Journal of Technology Transfer, 27(4), 339348. doi:http://dx.doi.org/I0.1023/a:102021 I606973.

ANTONELLI, C. (1985). The diffusion of an organizational innovation: international data telecommunications and multinational industrial firms. International Journal of Industrial Organization, 3(I), 109-II8. doi:http://dx.doi. org/10.1016/0167-7187(85)90017-7.

ARAUJO, C. Teixeira, A.C. (20/4). Determinants of International Technology Transfer: an Empirical Analysis of the Enterprise Europe Network, Journal of Technology Management \& Innovation, 9(3), I20-134. doi:http://dx.doi. org/I0.4067/s07/8-272420I4000300009.

BACH, L., Cohendet, P., Schenk, E. (2002). Technological transfer from the European space programs: a dynamic view and comparison with other R\&D projects, Journal of Technology Transfer, 27(4), 32I-338. doi:http://dx.doi. org/I0.1023/a: 1020259522902.

BOH,W.F.,Nguyen,T.T.,Xu,Y.(20I3).Knowledge transferacross dissimilar cultures. Journal of Knowledge Management, 17(I) , 29-46. doi:http://dx.doi.org// 0.I | 08//367327/3 | | 300723.

CHEN, J., Mahto, R., Lovvorn, Al S. (2013). Conceptual Framework of Knowledge Transfer within Multinational Corporations: A Strategic Orientation. International Journal of Management, 30(4), 322-339.

CUMMINGS, J. L., Teng, B. (2003). Transferring R\&D Knowledge: The Key Factors Affecting Knowledge Transfer Success. Journal of Engineering and Technology Management, 20(I-2), 39-68. doi:http://dx.doi.org//0.1016/s09234748(03)00004-3. 
CARMELI, A., Atwater, L., Levi, A. (20II). How leadership enhances employees' knowledge sharing: the intervening roles of relational and organizational identification. Journal of Technology Transfer, 36(3), 257-274. doi:http://dx.doi. org/ $/ 0.1007 / \mathrm{s} 10961-010-9154-y$.

DANA, M. (2007). Knowledge Transfer in Multinational Corporations. Management International Review 47(4), 567593. doi: http://dx.doi.org//0.1007/s I I575-007-0030-4.

DINUR, A., Hamilton, R.D., Inkpen, A.C. (2009). Critical context and international intrafirm best-practice transfers. Journal of International Management, 15(4), 432-446. doi:http://dx.doi.org//0.1016/j.intman.2008.07.003.

EISENHARDT, K.M. (1989). Building Theories from Case Study Research. The Academy of Management Review, I4(4), 532-550. doi:http://dx.doi.org//0.5465/amr. I989.4308385.

FUENTELSAZ, L., Gómez, J., Polo, Y. (2003). Intrafirm diffusion of new technologies: an empirical application. Research Policy, 32, 533-55I. doi:http://dx.doi.org//0.1016/ s0048-7333(02)0008I-I.

GIBSON, D., Smilor, R. (|99|). Key Variables in Technology Transfer: A Field-Study Based Empirical Analysis. Journal of Engineering and Technology Management, 8, 287-312. doi:http://dx.doi.org/I0.1016/0923-4748(9I)900I5-j.

GREINER, M.A., Franza, R.M. (2003). Barriers and Bridges for Successful Environmental Technology Transfer. The Journal of Technology Transfer, 28(2), 167-177. doi:http://dx.doi. org/| 0.1023/a: $1022998617 \mid 18$.

HANSEN, M.T., Løvås, B. (2004). How do multinational companies leverage technological competencies? Moving from single to interdependent explanations. Strategic Management Journal, 25(89), 80I-822. doi:http://dx.doi. org/l0.1002/smj.4I3.

HEDLUND, G. (1994). A model of knowledge management and the $\mathrm{N}$-form corporation. Strategic Management Journal, 15 (Issue Supplement S2), 73-90. doi:http://dx.doi. org/I0.1002/smj.4250I5I006.

HOLLENSTEIN, H.,Woerter, M. (2008). Inter- and intra-firm diffusion of technology: The example of E-commerce: An analysis based on Swiss firm-level data. Research Policy, 37 (3), 545-564. doi:http://dx.doi.org// 0.1016/j.respol.2007.12.006.
KOTABE, M., Xavier, M., Hiroshi D. (2003). Gaining from vertical partnerships: Knowledge transfer, relationship duration and supplier performance improvement in the U.S. and Japanese automotive industries. Strategic Management Journal, 24(4), 293-3/6. doi:http://dx.doi.org//0.1002/ smj.297.

LEE, J.Y., MacMillan, I.C., Choe, S. (2010). Technological knowledge transfer within chaebols after the 1997-98 crisis. Long Range Planning, 43, 585-6/0. doi:http://dx.doi. org/10.1016/j.lrp.2010.02.008.

MALIK, K. (2002). Aiding the Technology Manager: a conceptual model for intra-firm technology transfer. Technovation, 22(7), 427-436. doi:http://dx.doi.org/10.1016/ s0166-4972(0I)00030-x.

MCADAM, R. (2000). Knowledge management as a catalyst for innovation within organizations: a qualitative study, Knowledge and Process Management, 7(4 ), 233. doi:http:// dx.doi.org/ I 0. I002/ /099- I44 I (2000 I0/ I2)7:4<233::aidkpm94>3.0.co;2-f.

NARANJO -VALENCIA, J.C., Jiménez Jiménez, D., Sanz Valle, R. (20I I). Innovation or imitation? The role of organizational culture. Management Decision, 49(I), 55-72. doi:http:// dx.doi.org//0. I I08/0025 I 74 I I I 1094437.

O'SHEA, R.P., Allen, T.J., Chevalier, A., Roche, F. (2005). Entrepreneurial orientation, technology transfer and spin-off performance of U.S. universities. Research Policy, 34, 9941009. doi:http://dx.doi.org/I0.1016/j.respol.2005.05.01 I.

PETRONI, G., Venturini, K., Santini, S. (2010). Space technology transfer policies: Learning from scientific satellite case studies. Space Policy, 26(I), 39-52. doi:http://dx.doi. org/I0.1016/j.spacepol.2009.11.004.

ROGERS, E.M. (2005). Diffusion of Innovation (5th ed.), Free Press, New York.

SKARZAUSKIENE, A. (2010). Managing complexity: systems thinking as a catalyst of the organization performance. Measuring Business Excellence, 14(4), 49-64. doi:http:// dx.doi.org/I0.I I08/I368304 I0 I I093758.

STONEMAN, P.L., Myung-Joong K. (1996). Technology Adoption and Firm Profitability. Economic Journal, 106, 952962. doi:http://dx.doi.org// 0.2307/2235366.

SUNG, T.K., Gibson, D.V. (2000). Knowledge and Technology Transfer: Key Factors and Levels. Proceeding of 4th International Conference on Technology Policy and Innovation, 44 I-449. 
URATA, S., Kawai, H. (2000). Intrafirm Technology Transfer by Japanese Manufacturing Firms in Asia, in:The Role of Foreign Direct Investment in East Asian Economic Development, NBER-EASE, Vol. 9, Takatoshui Ito and Anne O. Krieger editors, University of Chicago Press, available http://www. nber.org/chapters/c8495.

VENTURINI, K., Verbano C., Matsumoto M. (2013). Space Technology Transfer: spinoff cases from Japan. Space Policy, 29(I), 49-57. doi:http://dx.doi.org//0.1016/j. spacepol.2012.11.010.

VERBANO C., Venturini K. (20I2). Technology Transfer in the Italian Space Industry: Organizational Issues and Determinants. Management Research Review, 35(3/4), 272288. doi:http://dx.doi.org/I0.1 I08/01409|7|21/210163. 